\section{Lars Edvinsson}

Received: 5 November 2001

Accepted in revised form: 10 January 2002

L. Edvinsson ( $\square)$

Department of Internal Medicine, University Hospital of Lund,

S-22185 Lund, Sweden

e-mail: lars.edvinsson@med.lu.se

Tel.: +46-46-171484

Fax: +46-46-184792

\section{Sensory nerves in the human cerebral circulation and trigeminal ganglion: role in primary headaches}

\begin{abstract}
Our knowledge of the nervous control of the cerebral circulation has increased by the use of denervations and retrograde tracing in combination with immunohistochemical techniques. We have demonstrated that cerebral vessels are supplied with sensory nerve fibers containing a multiplicity of transmitter substances originating in the trigeminal ganglion. The majority of these transmitters are neuropeptides, but the gaseous signal substance, nitric oxide (NO), is also included. In primary headaches, calcitonin generelated peptide (CGRP) is released in parallel with the headache, while the parasympathetic nerve transmitter
\end{abstract}

vasoactive intestinal peptide (VIP) is released in parallel with facial symtoms. Thus, the perivascular nerves participate in the pathogenesis of primary headaches. Current migraine drugs, e.g. triptans, act in part by inhibiting the release of CGRP from the sensory nerves.

Key words CGRP • Sensory nerves • Migraine - Cluster headache •

Trigeminovascular reflex

\section{Introduction}

With the advances in the understanding of cranial pain processing that have been made over the last few years it has become clear that cranial vessels have an important role in the expression of vascular pain syndromes such as migraine and cluster headache. Recent data show that specific populations of cerebrovascular sensory nerves are involved in the pathophysiology of these pain syndromes. The present review provides an account of my interpretation of available data on perivascular peptides in the pathogenesis of primary headaches. This includes a detailed description of the human cerebrovascular sensory innervation, the origin, immunocytochemical distribution and ultrastructural features of perivascular nerves and their role in primary headaches.

\section{A general view of the pathophysiology}

Current data provide a model in which a central "generator", different in migraine (Fig. 1) and in cluster headache, is activated. This may initiate a wave of "spreading depression" or vasoconstriction via amine-containing fibers originating in the brain stem [1]. Following alteration of cerebral blood vessel tone, the trigeminovascular reflex [2] is initiated to counter-balance cerebrovascular constriction, in part via release of calcitonin gene-related peptide (CGRP) and vasoactive intestinal peptide (VIP). The study of neuropeptide levels in migraine and cluster headache is now providing a link between clinical and basic research that is so crucial if the pathophysiology is to be understood (for more details see [3]). In migraine (with and without aura), marked 
changes in the cranial blood levels of CGRP indicate activation of the trigeminal system. These levels are normalized by the highly effective triptan antimigraine agents coincident with the relief of the headache. CGRP is released upon trigeminal nerve activation and the changes in peptide levels are also inhibited by triptans.

Activation of the trigeminal nucleus caudalis (TNC) provides the central link to nociception, pain development, and associated symptoms (Fig. 2). Hypothetically, intense acti- vation of the central pain pathways may involve the superior salivatory nucleus (SSN), resulting in parasympathetic VIP release, and manifestation of additional facial symptoms. This way of connecting known facts may be useful in our further work to explore the neural innervation of the cerebral and extracerebral vessels, which along with pharmacological studies of the transmitters involved may permit both an understanding of the pathogenesis of migraine and an even better treatment design.

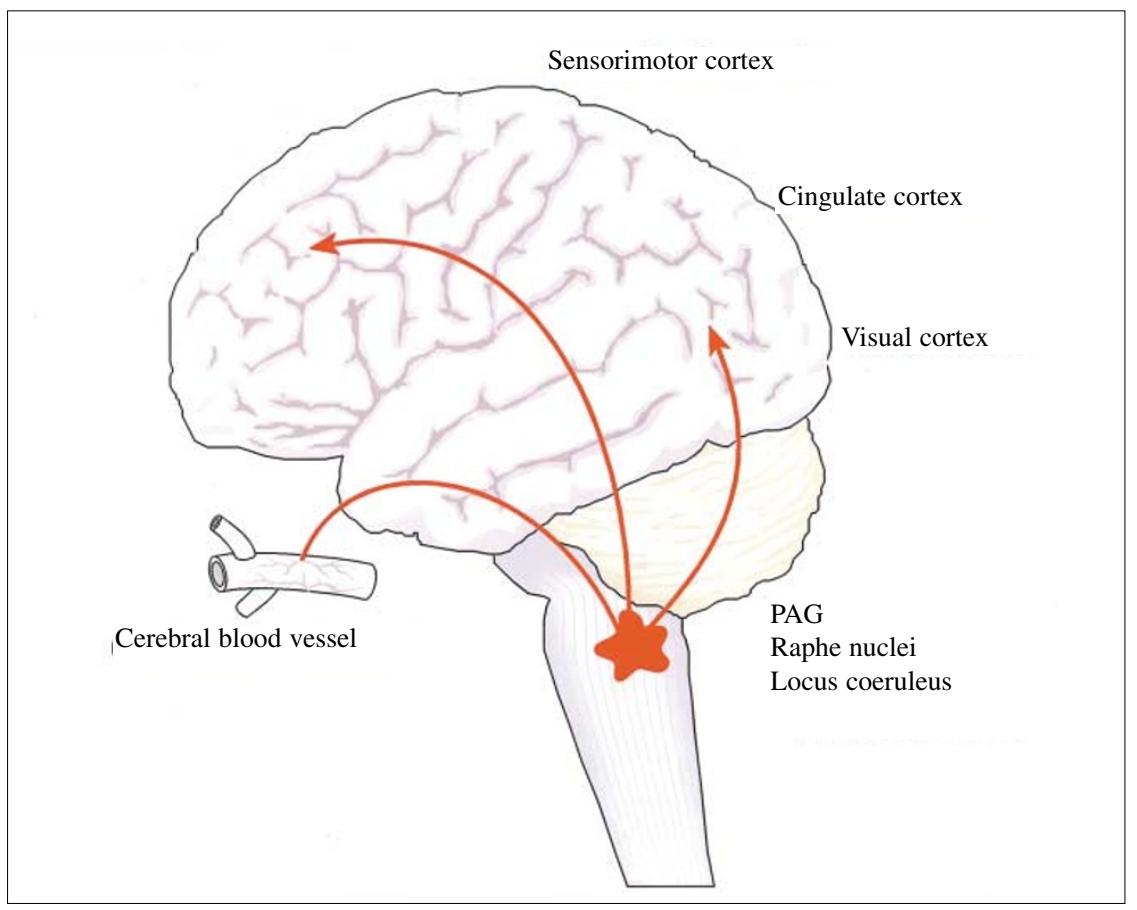

Fig. 1 Migraine locus in the brainstem is hypothetically activated and results in a wave of spreading depression over the brain, constricting the cerebral blood vessels. $P A G$, periaqueductal grey region
Fig. 2 Vasoconstriction may trigger the trigeminovascular reflex to cause an antidromic release of stored signal substances (CGRP, inter alia) and the activation of the trigeminal nucleus caudalis (TNC) with transmission of signals to the cerebrum. $T G$, trigeminal ganglion

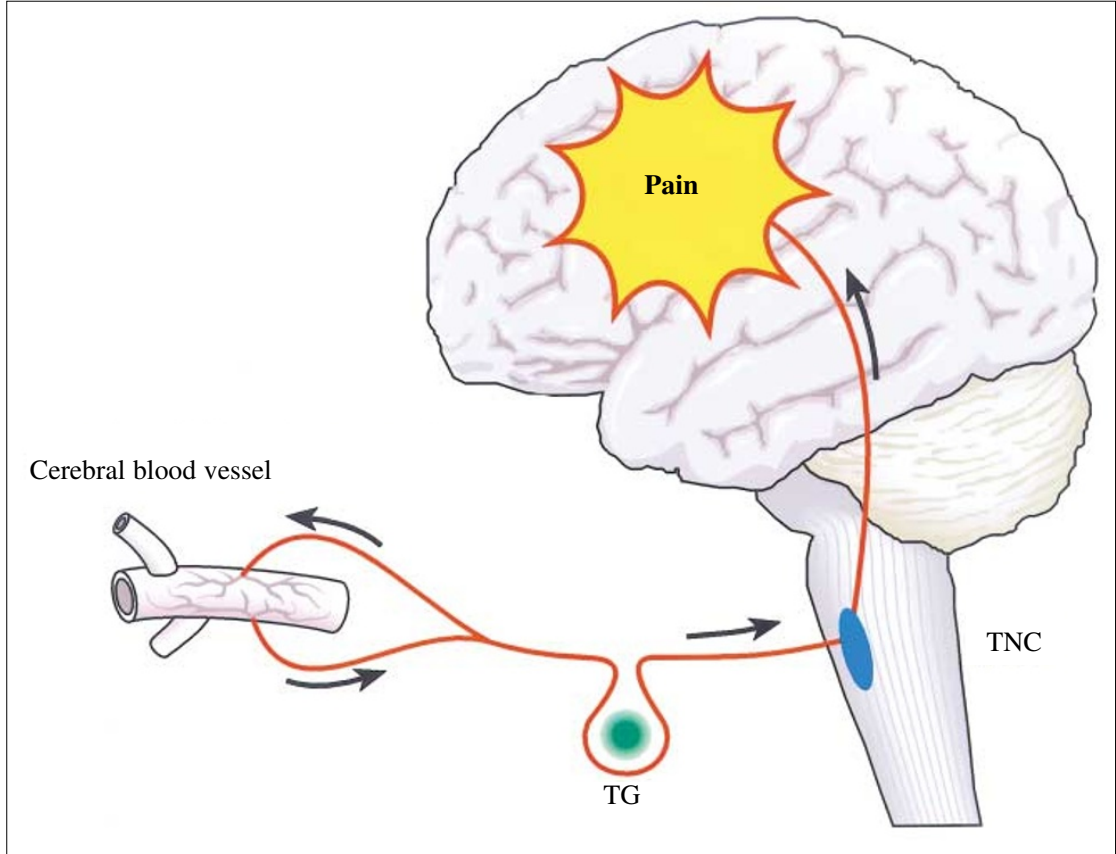




\section{The trigeminovascular system}

For many years, morphological studies of the sensory innervation of the cerebral vascular system were based on methylene blue staining and silver impregnation techniques. However, the results obtained were limited due to the fact that staining was inconsistent and did not allow the discrimination of subpopulations. Significant advances have been made in the morphological analysis of presumptive vascular nerve endings by the introduction of electron-microscopic methods. The presence of an unusual abundance of mitochondria within nerve varicosities has been repeatedly shown to be one of the most distinguishing features of the sensory nerve terminals. In rat cerebral arteries, mitochondria-rich nerve varicosities were interpreted as sensory in nature because they could be traced back to myelinated fibers $[4,5]$ and did not degenerate after sympathetic denervation by removal of the superior cervical ganglion [6]. Presumptive vascular sensory nerve terminals may contain, besides a large number of mitochondria, small clear and/or dense vesicles (30-60 nm in diameter) and large densecored vesicles (80-150 $\mathrm{nm}$ in diameter), autophagic vacuoles, pleomorphic dense bodies, lamellated or myelin figures, and large amounts of glycogen-like granules [7]. These nerve terminal varicosities have been postulated to represent nerve specializations for pressure or tension reception based on the structural analogy they share with sensory or baroreceptor nerve terminals [8]. However, the use of immunocytochemical techniques has increased our knowledge on the distribution of sensory nerve fibers supplying the vasculature. To date, the most widely distributed neuropeptides in afferent cerebrovascular nerve fibers are the neurokinins and CGRP $[2,9]$.

\section{Neurokinins}

Immunohistochemical studies have shown that substance $\mathrm{P}$ (SP), which is the best known neurokinin, is present in nerve fibers supplying cerebral vessels of a variety of species including man (Fig. 3) [10]. Although interspecies differences have not been systematically studied, cerebral arteries from guinea pig and cat receive a relatively dense supply of SP-immunoreactive nerve fibers $[11,12]$. Porcine cerebral arteries are innervated by a moderate nerve supply and cerebral vessels from humans, rabbits and rats appear to have a relatively sparse distribution of SP-containing nerve fibers. In general, SP immunoreactive nerve fibers are more abundant in anterior vessels of the circle of Willis, such as the anterior cerebral artery. Nerve fibers containing SP immunoreactivity are also associated with cerebral veins.

Retrograde tracing studies have demonstrated that the major source of cerebrovascular SP-containing nerve fibers is the trigeminal $[8,13]$, however, some of the perivascular nerve fibers may also originate in the upper cervical dorsal root ganglia $[13,14]$. Unilateral excision of the trigeminal ganglion in the cat decreases cerebrovascu-

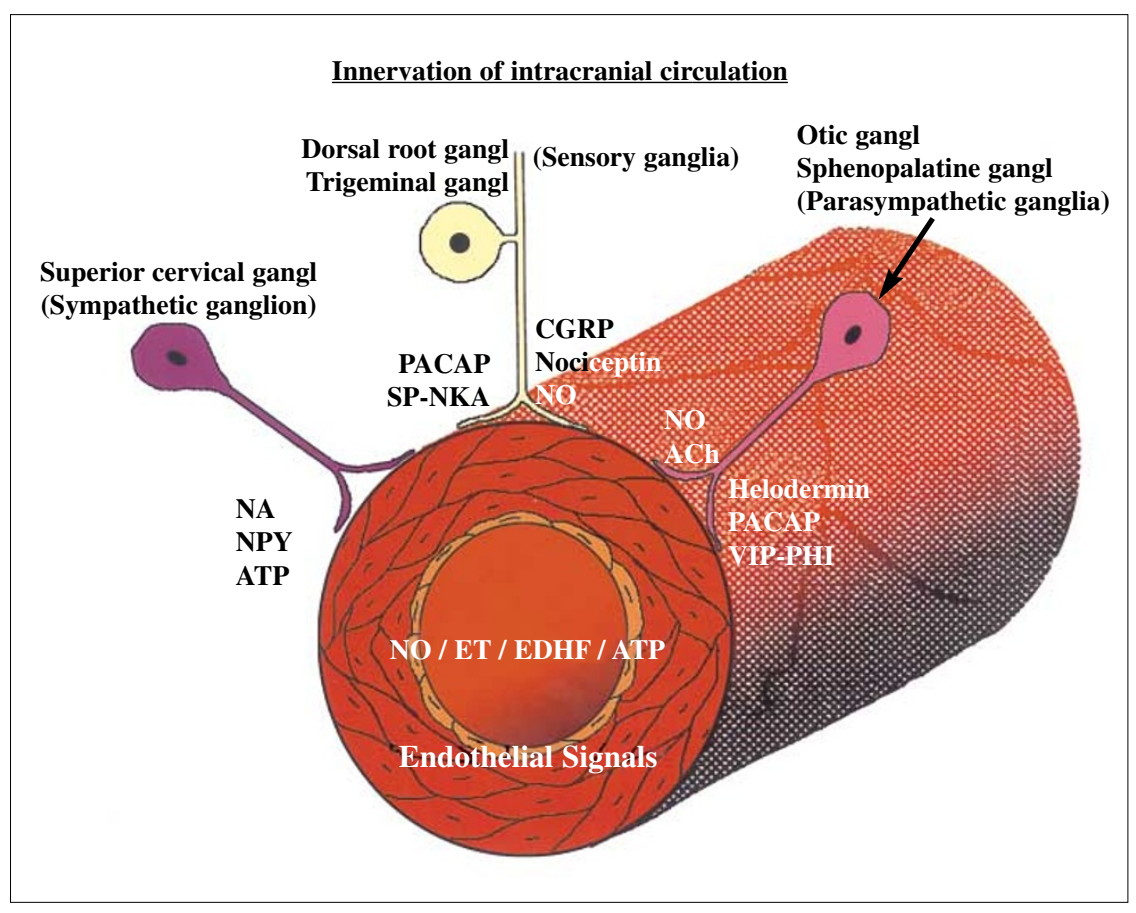

Fig. 3 Overview of the different types of innervation of brain vessels, by sympathetic, parasympathetic and sensory nerve fibers. The various signals substances are denoted for each nerve fiber type. $N A$, noradrenaline; $N P Y$, neuropeptide Y; PACAP, pituitary adenylate cyclase-activating polypeptide; $S P$ $N K A$, substance P neurokinin A; CGRP, calcitonin gene-related peptide; $A C h$, acetylcholine; VIP-PHI, vasoactive intestinal peptide peptide-histidine isoleucin; $E T$, endothelin; $E D H F$, endothelial derived hyperpolarizing factor 
lar SP levels and induces an almost complete loss of SPimmunoreactive nerve fibers in the wall of cerebral arteries $[2,15]$. The origin of SP-immunoreactive nerve fibers has been substantiated by using the sensory neurotoxin capsaicin. Systemic capsaicin treatment of guinea pigs leads to a marked loss of SP immunoreactivity in the cerebral vasculature [16]. However, capsaicin does not deplete SP immunoreactivity from rat brain microvessels [17]. This observation, together with the presence of substantial amounts of SP even after division of the trigeminal nerve, has led to the conclusion that while the trigeminal ganglion is the major source of SP in large cerebral arteries, it may not be the exclusive source of this neuropeptide in brain microvessels. For instance, in the dorsal raphe and interpeduncular nucleus, the dendrite processes of central perikarya containing SP immunoreactivity are intimately associated with small cerebral blood vessels [18].

Neurokinin A (NKA)-immunoreactive nerve fibers have a distribution similar to that of SP-containing nerves and are also depleted after capsaicin treatment [19]. Furthermore, NKA is co-localized with SP in cerebrovascular nerve fibers and in cell bodies in the trigeminal ganglion [19].

\section{Calcitonin gene-related peptide}

CGRP immunoreactivity is present in perivascular nerve fibers supplying the major cerebral arteries and pial arterioles of the cortical surface of several species including man $[2,13,14,15,20-24]$. Marked species and regional variations have been observed in the density of CGRPimmunoreactive cerebrovascular nerve fibers. While cerebral arteries of laboratory animals receive a relatively dense supply of CGRP-immunoreactive nerve fibers, human cerebral vessels are only innervated with a sparse nerve fiber network (Fig. 3). From surgical denervation studies, it appears that the trigeminal ganglion is the only source for the CGRP-containing cerebrovascular innervation $[2,13$, 15]. CGRP frequently coexists with SP and NKA in a population of sensory ganglion cells, although the number of CGRP-containing cells exceeds the number of SP/NKAcontaining neurons. CGRP immunoreactivity is often colocalized with SP/NKA immunoreactivity in perivascular nerve fibers supplying rodent and feline cerebral arteries $[15,19,25]$ and the human cerebral and temporal arteries $[7$, $21,22]$. These results are further supported at the ultrastructural level, where the use of double immunogold staining demonstrated that CGRP and SP immunoreactivities are consistently found co-localized in the same large granular vesicles (70-150 nm in diameter) in both sensory neurons of the trigeminal ganglion and in varicosities of perivascular nerve fibers $[5,7]$.

\section{PACAP and NOS}

Immunochemistry has revealed the occurence of pituitary adenylate cyclase-activating polypeptide (PACAP) in various parts of the sensory system, e.g. dorsal horn of the spinal cord, in cell bodies of spinal and trigeminal ganglia [26-28]. It coexists with SP and CGRP in fibers and ganglia. With in situ hybridization, mRNA for PACAP has been detected in these ganglia [28-30]. With the use of specific antibodies, my colleagues and I early noted the presence of PACAP immunoreactive nerve fibers in the cat cerebral circulation [31]. In a subsequent study the origin of the PACAP fibers in the rat was traced to the cranial ganglia [30], however, the majority of these reside in the parasympathetic ganglia. In the human trigeminal ganglion, PACAP-containing cell bodies were more numerous than in the laboratory animals, amounting to $15 \%$ [32]. Co-localization was seen with CGRP [30]. It is thus likely that PACAP may have a role also in the sensory system.

In the human sensory system there is also expression of nitric oxide synthase (NOS) in a subpopulation of CGRPcontaining cell bodies [32]. The origin and distribution of cerebrovascular nerve fibers containing NOS have been evaluated previously in several species [30, 33-37]. The perivascular innervation is denser in the rostral part of the circle of Willis as compared to vessels posteriorly located. In the human circle of Willis, the network of NOS-containing fibers is relatively sparse.

It has been proposed that the trigeminal ganglion in the rat harbors a significant population of NOS-containing nerve cell bodies [34]. In the rat up to $40 \%$ of the trigeminal cell bodies store CGRP $[13,14]$. In functional studies using NOS blockade (L-NAME), we could not reveal any modification of the increase in cerebral blood flow following trigeminal nerve stimulation [38]. On the other hand, the CGRP blocker CGRP $_{8-37}$ significantly attenuated trigeminal vasodilatation in situ, demonstrating a role for CGRP in this pathway. Thus, NOS-immunoreactive perivascular nerve fibers in the rostral part of the cerebral circulation originate mainly in the ipsilateral sphenopalatine and otic ganglia with a near complete colocalization of NOS-immunoreactivity with VIP- and PACAPimmunoreactivity. The role of $\mathrm{NO}$ in the sensory system is not clear although there is a suggestion that $\mathrm{NO}$ may be involved in the pathogenesis of primary headaches $[39,40]$.

\section{Neurotransmitters in primary headaches}

Trigeminal ganglion stimulation

The trigeminal system provides an important pain-sensitive link in the cranial vasculature. Studies examining what takes 
place when the sensory pathway is activated in animals have shown that they have no resting tonic influence on regional cerebral blood flow or regional cerebral metabolism [41] and that trigeminal ganglion stimulation increases intracranial blood flow [42]. In humans, unilateral stimulation of the trigeminal ganglion results in increased bilateral cortical blood flow, slightly more on the stimulated site than contralaterally [43]. Patients under treatment for trigeminal neuralgia are, in addition, noted to flush on the side of stimulation. This coincides with the release of CGRP and SP, a response that is interrupted following cessation of stimulation in our studies [44].

\section{Migraine attacks}

The levels of various neuropeptides in patients from the external jugular vein during migraine attacks. The concentrations of neuropeptide $\mathrm{Y}$ (a marker for sympathetic activity), VIP (parasympathetic activity) and CGRP or SP (markers for trigeminal activity) were initially measured. There were no changes in peripheral blood levels of any of the peptides (samples from the cubital fossa vein), while a marked increase in jugular vein CGRP was observed during migraine headache (Fig. 4) [45, 46]. There was no difference between migraine with aura or without aura; both resulted in substantial increases in venous CGRP levels [46, 47]. In addition, a somewhat higher basal level of CGRP was noted in the cubital fossa vein blood also outside the attack [48].
My view is that the release of CGRP may be due to the fact that the cerebral circulation is mainly innervated by CGRP from the trigeminal ganglion [13]. CGRP seems to be the main transmitter in the trigeminal ganglion and there is a large amount of CGRP-containing nerve fibers around central blood vessels $[2,15,21]$. It is, therefore, inevitable that CGRP plays a major role in nociception. The clinical observations of a release of CGRP during migraine has been confirmed in subsequent studies by others [47]. In addition, following sumatriptan administration, CGRP levels returned to control levels with successful amelioration of the headache [46].

\section{Cluster headache}

Cluster headache is a well-described clinical syndrome. Patients with episodic cluster headache, fulfilling the criteria of the International Headache Society (IHS), have been examined during acute spontaneous attacks of headache to determine the release of neuropeptides [49]. During the attacks, the levels of CGRP and VIP were raised in all subjects, while there were no changes in neuropeptide Y (NPY) or SP levels (Fig. 5). Treatment with oxygen or subcutaneous sumatriptan promptly normalized the CGRP levels, while administration of an opiate did not alter the peptide levels [49]. Two individuals with migraine symptoms similar to those seen in cluster headache (e.g. nasal congestion and rhinorrhea) also displayed increased levels of VIP, but this was

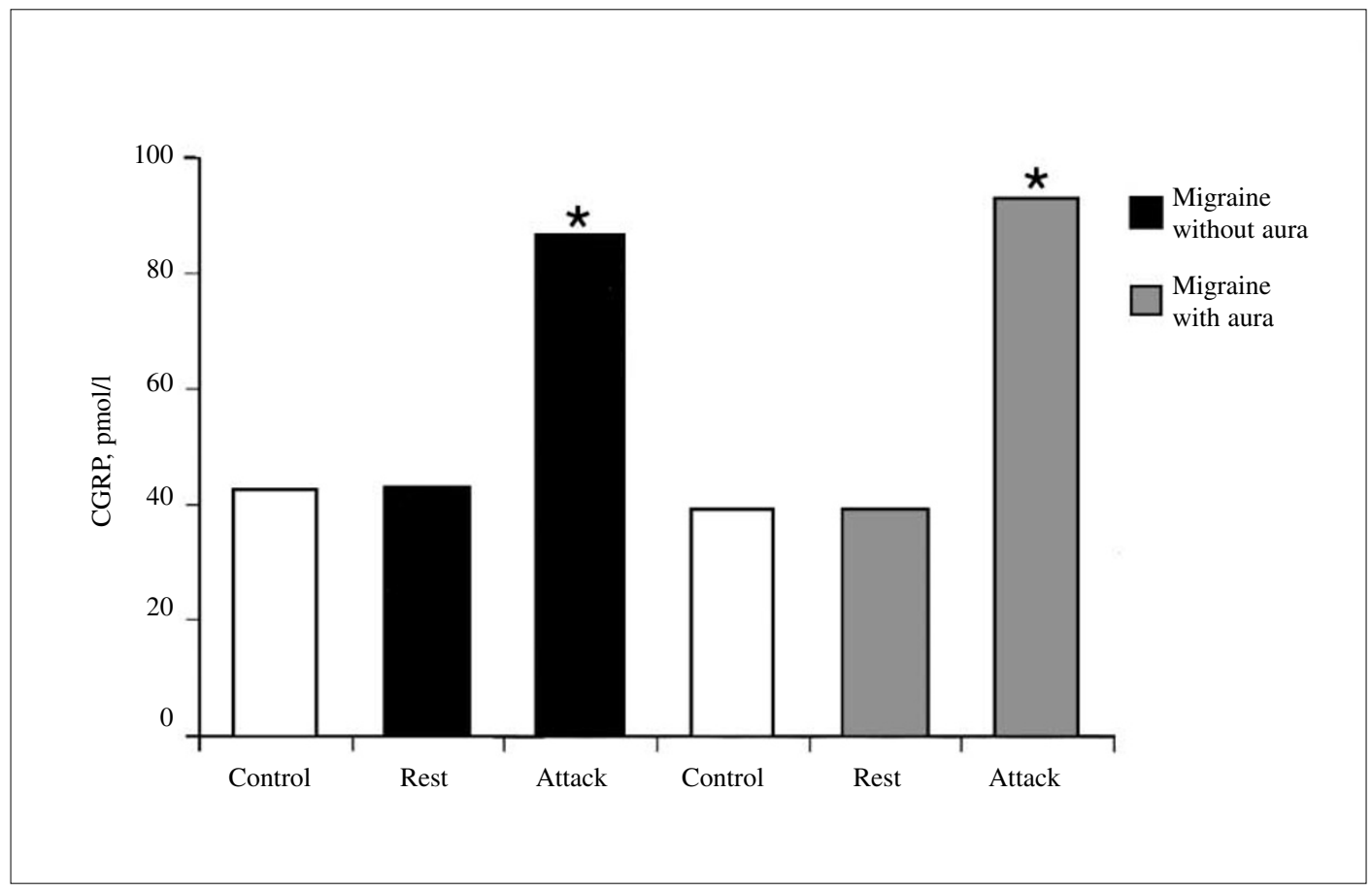

Fig. 4 Release of CGRP during migraine attacks. Simultaneous analysis of substance P, VIP and neuropeptide $\mathrm{Y}$ showed that these peptides remained at resting levels. *, $p<0.05$ (from [45] with permission) 


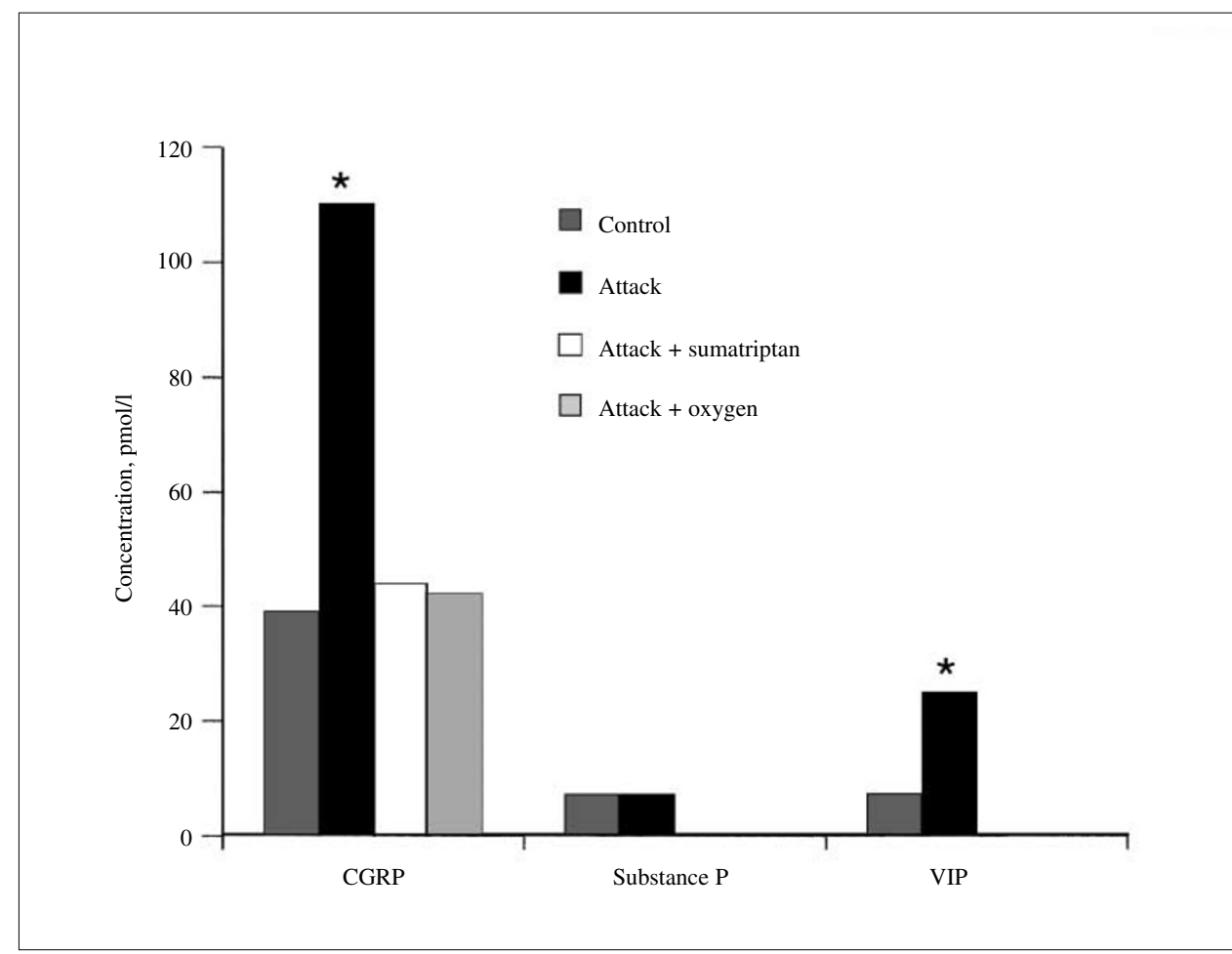

Fig. 5 Enhanced release of CGRP and VIP during attacks of cluster headache. Treatment with subcutaneous sumatriptan or inhalation of oxygen aborted the headache and the peptide release during the attacks. *, $p<0.05$ not the case in the whole group [45]. The changes in VIP suggested the involvement of a parasympathetically mediated event. The exact nature of this has been studied to some extent. Direct activation of the trigeminal ganglion in the cat results in release of both CGRP and VIP, and this effect is blunted by a triptan [50]. Activation of the trigeminovascular pathway by stimulation of the superior sagittal sinus also results in the release of CGRP and VIP [51]. This response was abolished when the trigeminal nerve was lesioned, suggestive of mediation via a brainstem reflex [51].

Clinical studies have shown that activation of the trigeminovascular system and the cranial parasympathetic nervous system plays a role in the acute attacks of cluster headache. It was particularly noteworthy that all subjects responded with release of VIP. This is in concert with the facial symptoms of this disorder. The findings agree well with the results of others [52] demonstrating release of CGRP in nitroglycerin-elicited attacks of cluster headache. Fanciullacci et al. [53] observed in another study that nitroglycerin could only elicit an attack of cluster headache with CGRP release if the patient was in a latent period and thus prone to activation. The finding of elevated levels of both CGRP and VIP in the cranial venous blood during the attacks and the cat experiments suggest that there is activation of a brainstem reflex, the afferent arc of which is the trigeminal nerve and the efferent the cranial parasympathetic outflow from the seventh cranial nerve.
Trigeminal neuralgia

When normal individuals were compared with patients with trigeminal neuralgia [44], there was no difference between the resting levels of neuropeptides in cranial venous outflow. Stimulation of the trigeminal ganglion in conjunction with thermocoagulation caused a marked increase in the blood levels of CGRP and SP, which was associated with unilateral facial flushing. After cessation of the stimulation, the peptide levels returned to normal.

Vasoactive substances may be responsible not only for causing headache but also for causing neurally mediated facial flushing. Local facial stimulation by tapping a painful trigger point of a patient with a 17-year history of intractable left-sided facial pain led to both pain and flushing [54]. This was associated with a marked increase (120\%) in CGRP levels during the flushing with no change in SP, NPY or VIP levels. Thus, the CGRP release was linked with unilateral headache also in this subject.

Chronic paroxysmal hemicrania

Chronic paroxysmal hemicrania $(\mathrm{CPH})$ is a relatively wellrecognized syndrome that is defined by the IHS operational 
diagnostic criteria as frequent short-lasting attacks of unilateral pain usually in the orbital, supra-orbital or temporal regions that may last for 2-45 minutes. The attack frequency may vary but is usually five or moretimes each day. The pain is associated with prominent autonomic symptoms such as conjunctival injection, lacrimation, nasal congestion, rhinorrhoea, ptosis or eyelid edema. According to the diagnostic criteria, the attacks settle rapidly upon treatment with indomethacin.

My colleagues and I have studied one such case and observed that, during the pain, the CGRP level rose to 123 $\mathrm{pmol} / \mathrm{l}$ compared to a level of $41 \mathrm{pmol} / \mathrm{l}$ while on indomethacin or in control subjects [44-46, 49]. The VIP level rose to $32 \mathrm{pmol} / \mathrm{l}$ during an attack, dropping to 7 $\mathrm{pmol} / 1$ upon indomethacin treatment [55]. This case report and accompanying data show that attacks of $\mathrm{CPH}$ are characterized by activation of both sensory and parasympathetic cranial nerve fibers. The neuropeptides were at normal levels when the headaches were controlled on indomethacin. Thus, studies of neuropeptide markers in $\mathrm{CPH}$ serve as biological markers. The results also illustrate the possibility that different primary headache syndromes share a similar pathophysiology. Future work will help us to further understand the neurobiology of primary headache disorders.

Acknowledgement This work was supported in part by grant no. 5958 of the Swedish Research Council.

\section{References}

1. Edvinsson L, Deguerce A, Duverger D, MacKenzie ET, Scatton B (1983) Central serotonergic nerves project to the pial vessels of the brain. Nature 306:55-57

2. McCulloch J, Uddman R, Kingman TA, Edvinsson L (1986) Calcitonin gene-related peptide: functional role in cerebrovascular regulation. Proc Natl Acad Sci USA 83:5731-3735

3. Edvinsson L (2001) Aspects on the pathophysiology of migraine and cluster headache. Pharmacol Toxicol 89:65-73

4. Iwayama T, Furness J B, Burnstock G (1970) Dual adrenergic and cholinergic innervation of the cerebral arteries of the rat. Circ Res 26:635-646

5. Gulbenkian S, Wharton J (1993) Pattern of innervation of sensory afferent systems in the circulation: immunocytochemistry and ultrastructure. In: Edvinsson, L, Uddman R (eds) Vascular innervation and receptor mechanisms. Academic, San Diego, pp 247-262

6. Gulbenkian S, Merighi A, Wharton J, Varndell I, Polak JM (1986)

Ultrastructural evidence for the coexistence of calcitonin gene-related peptide and substance $\mathrm{P}$ in secretory vesicles of peripheral nerves in the guinea pig. J Neurocytol 15:535-542

7. Jansen-Olesen I, Gulbenkian S, Valença A, Antunes JL, Wharton J, Polak JM, Edvinsson L (1995) The innervation of the human superficial temporal artery. Peptides 16:275-287

8. Liu-Chen LY, Mayberg MR, Moskowitz MA (1983)

Immunohistochemical evidence for a substance P-containing trigeminovascular pathway to pial arteries in cats. Brain Res 268:162-166
9. Mayberg M, Langer RS, Zervas NT, Moskowitz MA (1981) Perivascular meningeal projections from cat trigeminal ganglia: Possible pathway for vascular headache in man. Science 231:228-230

10. Edvinsson L, Krause DN (2002) Cerebral blood flow and metabolism. Lippincott Williams Wilkins, Philadelphia

11. Edvinsson L, McCulloch J, Uddman R (1981) Substance P: immunohistochemical localization and effect upon cat pial arteries in vitro and in situ. $\mathbf{J}$ Physiol (London) 318:251-258

12. Edvinsson L, Rosendahl-Helgesen S, Uddman R (1983) Substance P. Localization, concentration and release in cerebral arteries, choroid plexus and dura mater. Cell Tissue Res 234:1-7

13. Edvinsson L, Hara H, Uddman R (1989) Retrograde tracing of nerve fibers to the rat middle cerebral artery with true blue: Colocalization with different peptides. $\mathrm{J}$ Cereb Blood Flow Metab 9:212-218

14. Suzuki N, Hardebo JE, Owman C (1989) Origins and pathways of cerebrovascular nerves storing substance $\mathrm{P}$ and calcitonin gene-related peptide in rat. Neuroscience 31:427-438

15. Uddman R, Edvinsson L, Ekman R, Kingman T, McCulloch J (1985) Innervation of the feline cerebral vasculature by nerve fibers containing calcitonin gene-related peptide: trigeminal origin and coexistence with substance P. Neurosci Lett 62:131-136

16. Duckles SP, Buck SH (1982) Substance $\mathrm{P}$ in the cerebral vasculature: depletion by capsaicin suggests a sensory role. Brain Res 245:171-174
17. Helps S, Reilly P (1985) Cerebral blood flow response to carbon dioxide after capsaicin treatment. J Cereb Blood Flow Metab 5[Suppl]:S503-S504

18. Kapadia SE, De lanerolle NC (1984) Immunohistochemical and electron microscopic demonstration of vascular innervation in the mammalian brain stem. Brain Res 292:33-39

19. Edvinsson L, Brodin E, Jansen I, Uddman R (1988) Neurokinin A in cerebral vessels: characterization, localization, co-existence and effects in vitro. Regul Peptides 20:181-197

20. Matsuyama T, Wanaka A, Yoneda S, Kimura K, Kamada T, Girgis S, MacIntyre I, Emson PC, Toyama M (1986) Two distinct calcitonin generelated peptide-containing peripheral nervous systems: distribution and quantitative differences between the iris and cerebral artery with special reference to substance P. Brain Res 373:205-212

21. Edvinsson L, Jansen I, Cuncha e Sà M, Gulbenkian S (1994) Demonstration of neuropeptide-containing nerves and vasomotor responses to perivascular peptides in human cerebral arteries. Cephalalgia 14:88-96

22. Gulbenkian S, Barroso CP, Cunha e Sá M, Edvinsson L (1995) The peptidergic innervation of human coronary and cerebral vessels. Ital J Anat Embryol 100[Suppl 1]:S317-S327

23. Edvinsson L (1985) Functional role of perivascular peptides in the control of cerebral circulation. Trends Neurosci 8:126-131 
24. You J, Gulbenkian S, Jansen-Olesen I, Marron K, Wharton J, Barroso CP, Polak JM, Edvinsson L (1995) Peptidergic innervation of guinea pig brain vessels: comparison with immunohistochemistry and in vitro pharmacology in rostrally and caudally located arteries. J Auton Nerv Syst 55:179-188

25. Fricke B, Düring M von, Andres KH (1997) Topopgraphy and immunocytochemical characterization of nerve fibres in the leptomeningeal compartments of the rat. A light and electronmicroscopical study. Cell Tissue Res 287:11-22

26. Moller H, Zhang YZ, Hakanson R, Luts A, Sjolund B, Uddman R, Sundler F (1993) Pituitary adenylate cyclase activating polypeptide is a sensory neuropeptide: immunocytochemical and immunochemical evidence. Neuroscience 57:725-732

27. Mulder H, Uddman R, Moller K, Elsas T, Ekblad E, Alumets J, Sundler F (1995) Pituitary adenylate cyclase activating polypeptide is expressed in autonomic neurons. Regul Pept 59:121-128

28. Uddman R, Mulder H, Sundelin Elsas T, Sundler F (1994) Nitric oxide synthase expression in cervical autonomic and sensory ganglia in rat: relationship to neuropeptides. Cell Vision 1:306-312

29. Uddman R, Goadsby PJ, Jansen I, Edvinsson L (1994) Vasoactive intestinal peptide (VIP) like peptides in the cerebral circulation of the cat. J. Auton. Nerv Syst 49[Suppl]:S9-S103

30. Edvinsson L, Elsås T, Suzuki N, Shimizu T, Lee TJF (2001) Origin and co-localization of nitric oxide synthase, CGRP, PACAP, and VIP in the cerebral circulation of the rat. Microsc Res Tech 53:221-228

31. Uddman R, Goadsby PJ, Jansen I, Edvinsson L (1993) PACAP, a VIP-like peptide: immunohistochemical localization and effect upon cat pial arteries and cerebral blood flow. J Cereb Blood Flow Metab 13:291-297

32. Tajti J, Uddman R, Möller S, Sundler F, Edvinsson L (1999) Messenger molecules and receptor mRNA in the human trigeminal ganglion. J Auton Nerv Syst 76:176-183

33. Yoshida K, Okamura T, Kimura H, Bredt DS, Snyder SH (1993) Nitric oxide synthase immunoreactive nerve fibres in dog cerebral and peripheral arteries. Brain Res 629:67-72
34. Nozaki K, Moskowitz MA, Maynard K, Koketsu N, Dawson TM, Bredt DS, Snyder SH (1993) Possible origins and distribution of immunoreactive nitric oxide synthase-containing nerve fibers in cerebral arteries. J Cereb Blood Flow Metab 13:70-79

35. Yoshida K, Okamura T, Toda N (1994) Histological and functional studies on the nitroxidergic nerve innervating monkey cerebral, mesenteric and temporal arteries. Jpn J Pharmacol 65:351-359

36. Barroso CP, Edvinsson L, Zhang W, Cunha e Sá M, Springall DR, Polak JM, Gulbenkian S (1996) Nitroxidergic innervation of guinea pig cerebral arteries. J Auton Nerv Syst 58:108-114

37. Tomimoto H, Nishimura M, Suenaga T (1994) Distribution of nitric oxide synthase in the human cerebral blood vessels and brain tissues. J Cereb Blood Flow Metab 14:930-938

38. Edvinsson L, Mulder H, Goadsby PJ, Uddman R (1998) Calcitonin generelated peptide and nitric oxide in the trigeminal ganglion: cerebral vasodilation from trigeminal nerve stimulation involves mainly calcitonin gene-related peptide. J Auton Nerv Syst 70:15-22

39. Olesen J, Thomsen LL, Lassen LH, Olesen IJ (1995) The nitric oxide hypothesis of migraine and other vascular headaches. Cephalalgia 15:94-100

40. Lassen LH, Thomsen LL, Olesen J (1995) Histamine induces migraine via the H1-receptor. Support for the hypothesis of migraine. Neuroreport 6:1475-1479

41. Edvinsson L, McCulloch J, Kingman TA, Uddman R (1986) On the functional role of the trigemino-cerebrovascular system in the regulation of cerebral circulation. In: Owman C, Hardebo JE (eds) Neural regulations of the cerebral circulation. Elsevier, Amsterdam, pp 407-418

42. Goadsby PJ, Lambert GA, Lance JW (1986) Stimulation of the trigeminal ganglion increases flow in the extra cerebral but not the cerebral circulation of the monkey. Brain Res 381:63-67

43. Tran-Dinh YR, Thurei CG, Cunin A, Serrie JS (1992) Cerebral vasodilation after the thermocoagulation of the trigeminal ganglion in humans. Neurosurgery 31:658-62
44. Goadsby PJ, Edvinsson L, Ekman R (1988) Release of vasoactive peptide in the extracerebral circulation of humans and the cat during activation of the trigeminovascular system. Ann Neurol 23:193-196

45. Goadsby PJ, Edvinsson L, Ekman R (1990) Vasoactive peptide released in the extracerebral circulation of humans during migraine headache. Ann Neurol 28:183-187

46. Goadsby PJ, Edvinsson L (1993) The trigeminovascular system and migraine: studies characterizing cerebrovascular and neuropeptide changes seen in human and cats. Ann Neurol 33:48-56

47. Gallai V, Sarchielli P, Floridi A, Franceschini M, Codini M, Glioti G, Trequattrini A, Palumbo R (1995) Vasoactive peptide levels in the plasma of young migraine patients with and without aura assessed both interictally and ictally. Cephalalgia 15:384-390

48. Ashina M, Berndtesen L, Jensen R et al (2000) Evidence for increased plasma levels of calcitonin gene-related peptide in migraine outside of attacks. Pain 86:133-138

49. Goadsby PJ, Edvinsson L (1994) Human in vivo evidence for trigeminovascular activation in cluster headache. Neuropeptide changes and effects of acute therapies. Brain 117:427-434

50. Goadsby PJ, Edvinsson L (1994) Peripheral and central trigeminovascular activation in cat is blocked by the serotonin (HT)-ID receptor agonist 311C90. Headache 34:394-399

51. Zagami AS, Goadsby PJ, Edvinsson L (1990) Stimulation of the superior sagittal sinus in the cat causes release of vasoactive peptides. Neuropeptides 16:69-75

52. Fanciullacci M, Alessandri M, Figini $M$ et al (1995) Increases in plasma calcitonin gene-related peptide from extracerebral circulation during nitroglycerin-induced cluster attack. Pain 60:119-123

53. Fanciullacci M, Alessanri M, Sicuteri R, Marabini S (1997) Responsiveness of the trigeminovascular system to nitroglycerine in cluster headache patients. Brain 120:283-288

54. Goadsby PJ, Edvinsson 1, Ekman R (1992) Cutaneous sensory stimulation leading to facial flushing and release of calcitonin gene-related peptide. Cephalalgia 12:53-56 